\title{
Foundation for Heavy Lift-Early Developments in the Ares V Launch Vehicle
}

\author{
J. Craig McArthur, Acting Manager, and Bill Pannell, Systems Engineer \\ Core Stage Element Office \\ Exploration Launch Projects Office \\ NASA Marshall Space Flight Center \\ Huntsville, AL 35812
}

\begin{abstract}
The Ares V Cargo Launch Vehicle (CaLV) is NASA's primary vessel for safe, reliable delivery of the Lunar Surface Access Module (LSAM) and other resources into Earth orbit, as articulated in the U.S. Vision for Space Exploration. ${ }^{1}$ The Ares V launch concept is shown in Figure 1. The foundation for this heavy-lift companion to the Ares I Crew Launch Vehicle (CLV) is taking shape within NASA and with its government and industry partners. This paper will address accomplishments in the Ares V Launch Vehicle during 2006 and 2007 and offer a preview of future activities.
\end{abstract}

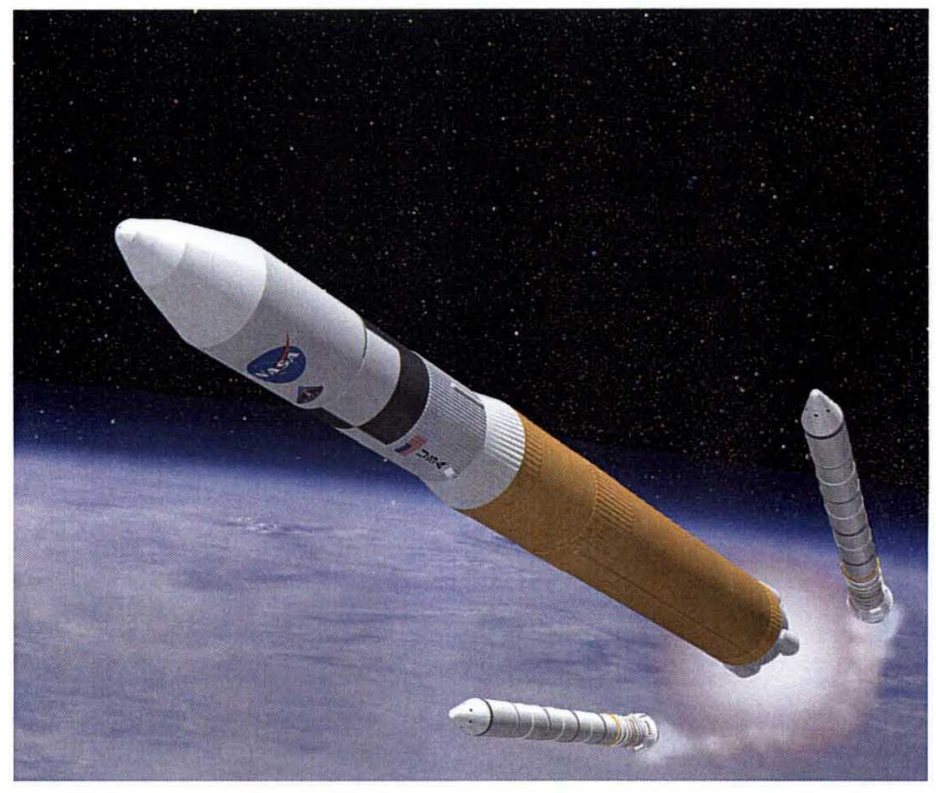

Figure 1. Ares V launch concept.

When it stands on the launch pad at Kennedy Space Center late in the next decade, the Ares V stack will be almost 360 feet tall (Figure 2). It will lift 136 metric tons (300,000 pounds) to a 30-by-160 nautical mile orbit at 28.5degrees inclination, or 55 metric tons $(120,000$ pounds) to trans-lunar injection. As first envisioned by the Exploration Systems Architecture Study (ESAS) in summer 2005, the Ares V consisted of two 5-segment Reusable Solid Rocket Boosters (RSRB) flanking a 27.5-foot-diameter Space Shuttle-derived External Tank (ET) delivering liquid hydrogen/liquid oxygen (LOX/LH2) to a cluster of five RS-25 Space Shuttle Main Engines (SSME), redesigned to be low-cost and expendable. ${ }^{2}$ The upper stage, known as the Earth Departure Stage (EDS), would be powered by two LOX/LH2 J-2S engines, evolved from the J-2 engine used in the Saturn launch vehicle upper stages. 


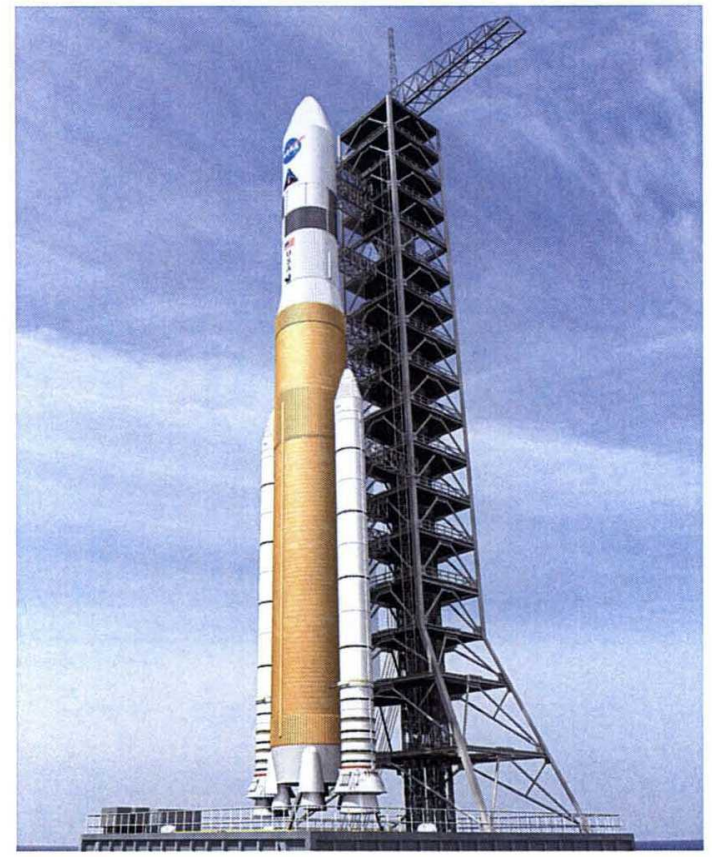

Figure 2. NASA concept of the Ares V on the launch pad.

As part of NASA's systems engineering approach, Marshall Space Flight Center's Exploration Launch Projects Office in early 2006 streamlined its Ares I design, development, test, and evaluation (DDT\&E) hardware plan so that the first stage booster and upper stage engine are largely extensible to the Ares $\mathrm{V}$ booster stage and EDS propulsion elements, saving billions in nonrecurring costs. Figure 3 shows the launch vehicles' common elements. The RS-25 also was replaced by the LOX/LH2 RS-68 engine, developed by the U.S. Air Force and currently in use on the Boeing Delta IV heavy-lift vehicle, reducing technical, schedule, and cost risk. The benefits and challenges of using common hardware are documented in the CLV/CaLV Commonality Assessment. ${ }^{3}$

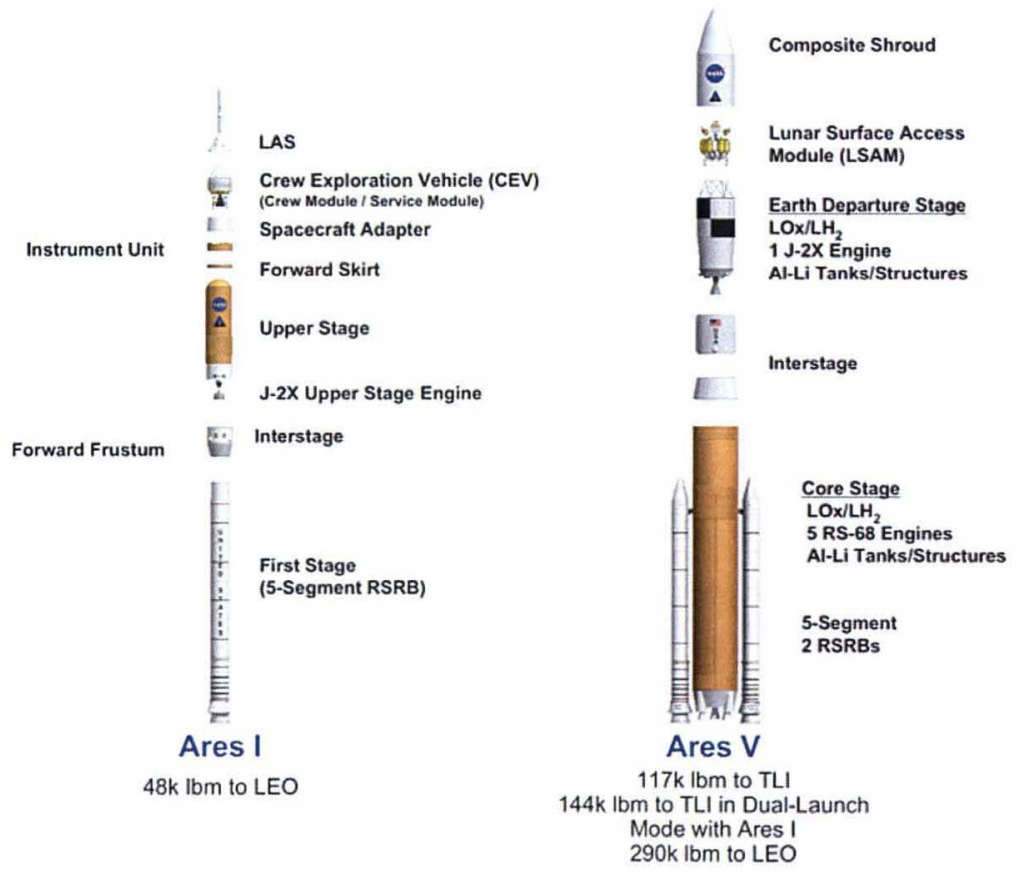

Figure 3. Expanded views of Ares I and Ares V show common hardware. 
The RS-68 is the most powerful liquid oxygen/liquid hydrogen booster in existence, capable of producing 650,000 pounds of thrust at sea level. In contrast, the SSME is capable of producing 420,000 pounds of thrust at sea level, although it operates at a higher level of efficiency than the RS-68. The ESAS had initially rejected the RS-68 because its lower specific impulse (Isp) and size were not compatible with the 27.5 -foot core stage propellant tank and payload requirements of the reference Ares V. The ESAS theorized that the high-performance RS- 25 might be redesigned as an expendable model (RS-25F) to reduce manufacturing costs by roughly half. However, current estimates suggest that the RS-68 modified to meet NASA standards will cost significantly less than a modified SSME. This represents a major savings on recurring costs, especially considering that each Ares $V$ mission will use five main engines at a nominal rate of two missions annually over a decade.

Further analyses show the cost, technical, schedule, and safety and reliability risks associated with redesigning and mass-producing the RS-25 are greater than the risks and costs associated with scaling up the Ares V Core Stage from 27.5 feet to 33 feet to hold the additional propellants needed to accommodate the RS-68 engine's reduced Isp and make room for the larger nozzle and exhaust clearances needed for the five-engine cluster. Analyses also noted that the RS-68 production line was developed with a goal of delivering 40 engines annually and is currently delivering 7 per year for Department of Defense and commercial missions. Additionally, improvements proposed by Boeing will make it feasible for the RS-68 to exceed the Ares V payload requirements.

Due to schedule and budget priorities, Ares V design remains at an earlier stage in development than Ares I. Many of the technical successes of the Ares I during the past year involving the 5-segment RSRB and J-2X engine are shared by the Ares $\mathrm{V}$ because of the decision to maximize commonality between the two launch vehicles. NASA has completed studies to determine mutual requirements between the Ares I and Ares V systems. Engineering analyses are under way on induced loads, structural dynamics, aerodynamics, base heating, and acoustics. Additionally, studies are now under way on how the switch to a 33-foot tank will affect manufacturing tooling at Michoud Assembly Facility and operations at Kennedy Space Center. However, most of the Ares V activity to date is related to the RS-68 engine.

NASA and the U.S. Air Force Space and Missile Center are currently pursuing an interagency agreement to develop RS-68A and RS-68B variants, respectively, of the RS-68 engine for the Delta IV and Ares V, leveraging the work of each organization in a synergistic fashion (Figure 4). For example, the Air Force is investigating fixes for known issues, such as turbine blade cracking, eliminating gas generator igniter debris, bearing material changes, cavitation suppression, and improved temperature and hot gas sensors, while NASA is exploring modifications such as reducing free hydrogen around the Core Stage base at ignition, reduced helium purge usage, and development of a long-duration nozzle. This arrangement reduces NASA's DDT\&E investments and provides a unique opportunity to obtain early flight data from Delta IV missions, reducing technical and schedule risk. The Air Force benefits from additional risk reduction testing and NASA-funded performance improvements. 


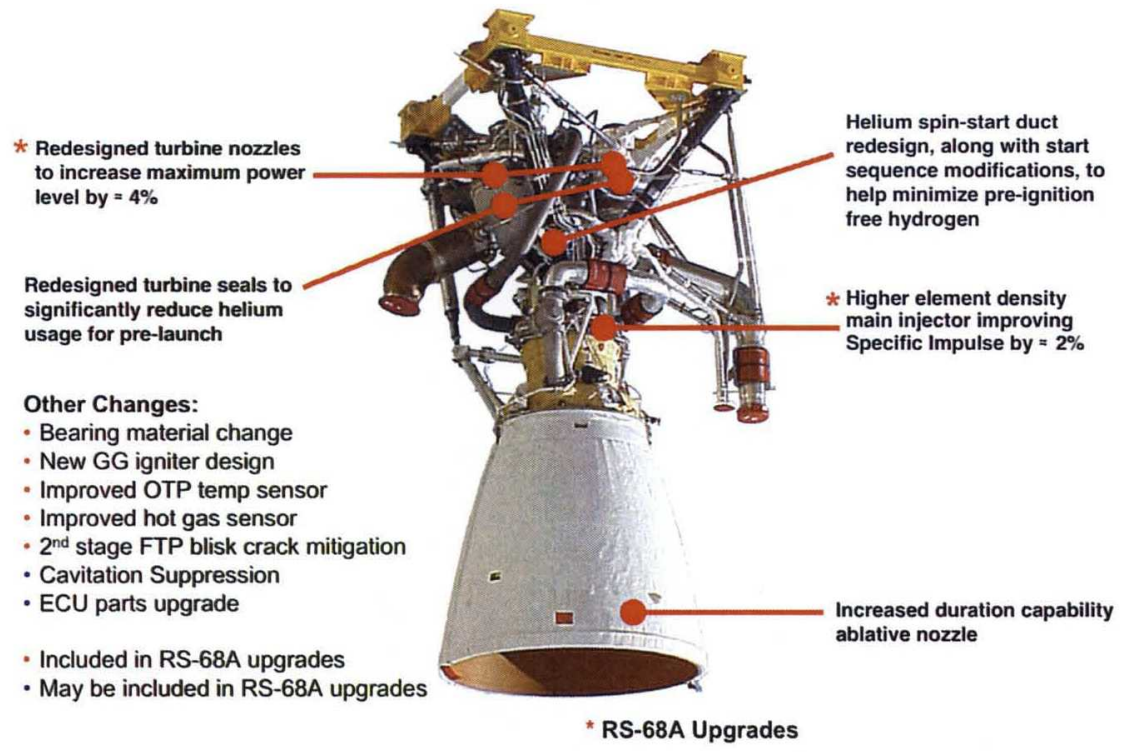

Figure 4. RS-68 engine, showing major planned modifications.

The U.S. Vision for Space Exploration sets a goal of returning to the Moon no later than 2020 and extending the human presence across the solar system and beyond. The work already under way on the Ares V Core Stage is on track to meet that commitment.

\section{$\underline{\text { References }}$}

1 National Aeronautics and Space Administration. The Vision for Space Exploration. February 2004, www.nasa.gov/mission_pages/exploration/main/

${ }^{2}$ National Aeronautics and Space Administration. NASA's Exploration Systems Architecture Study Final Report. NASA-TM-2005-214062. November 2005.

${ }^{3}$ NASA Exploration Launch Projects Crew Launch Vehicle/Cargo Launch Vehicle Commonality Assessment, May 2006. 


\section{Exploration Launch Projects}

Foundation for Heavy Lift Early DeVelopments in the Ares Launch Vehicle

John P. Sumrall

Manager, Advanced Planning Marstiall Space Flight Center

J. Craig MCArthur

Acting Manager, Ares V Core Stage Element Office Marshall Space Flight Genter

Matt Lacey

Aerospace Engineer

Marshall Space Flight Center

AIAA Joint Propulsion Conference

July 2007

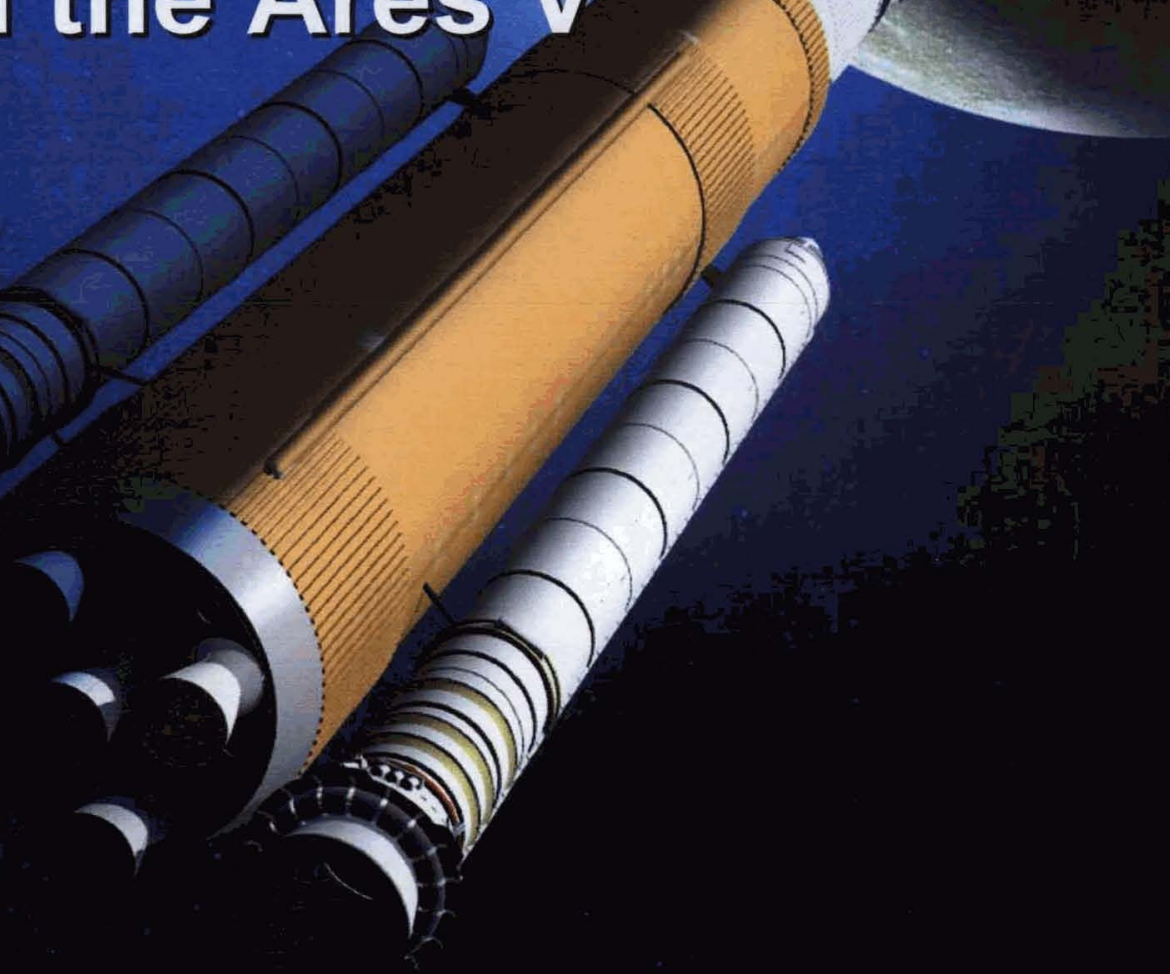

www.nasa.gov 


\section{Agenda}

- Overview of the Ares Launch Vehicles

- Ares V design approach \& evolution

-2006-2007 progress

- Forward work and conclusions 


\section{Building on a Foundation of Proven Technologies \\ - Launch Vehicle Comparisons -}

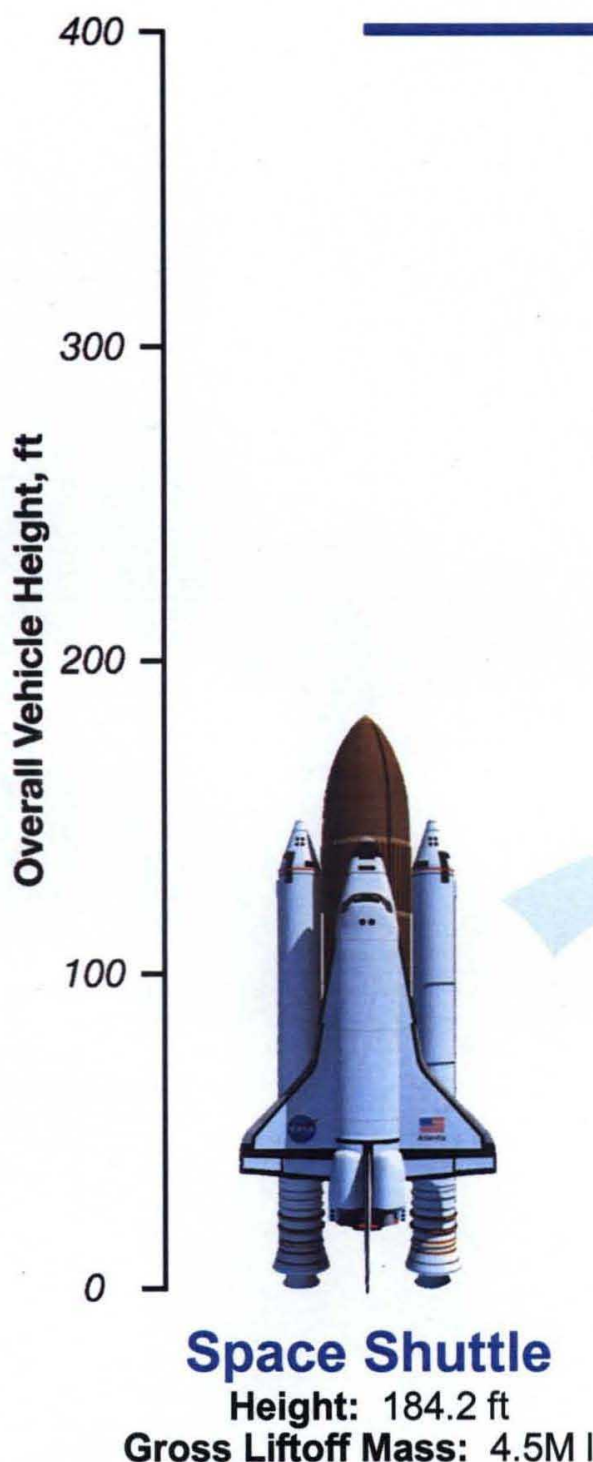

Gross Liftoff Mass: $4.5 \mathrm{M} \mathrm{lb}$

$55 \mathrm{k} \mathrm{lbm}$ to LEO

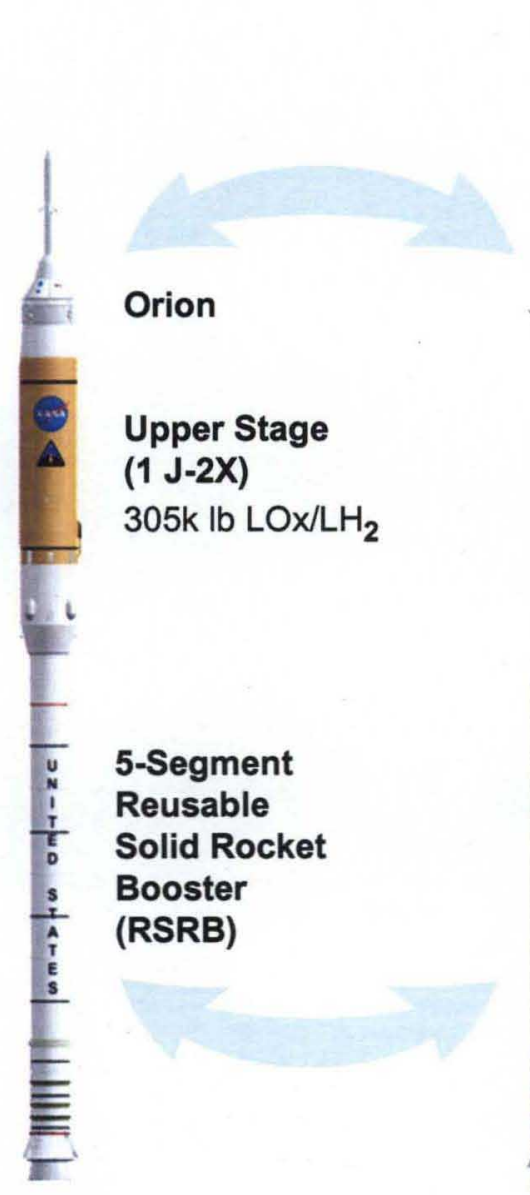

Ares I

Height: $328 \mathrm{ft}$

Gross Liftoff Mass: $2.0 \mathrm{M} \mathrm{lb}$

\section{$52 \mathrm{k} \mathrm{lbm}$ to LEO (effective)}

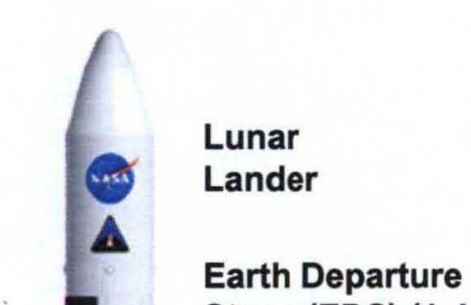

\section{Earth Departure}

Stage (EDS) (1 J-2X)

$493 \mathrm{k} \mathrm{lb} \mathrm{LOx/LH_{2 }}$

Core Stage

(5 RS-68 Engines)

3.1M lb LOx/LH

\section{5-Segment}

2 RSRB's

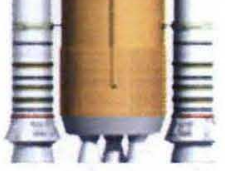

\section{Ares V}

Height: $362 \mathrm{ft}$

Gross Liftoff Mass: $7.3 \mathrm{M} \mathrm{lb}$

$133-144 \mathrm{k}^{*} \mathrm{Ibm}$ to TLI in

Dual-Launch Mode with Ares I

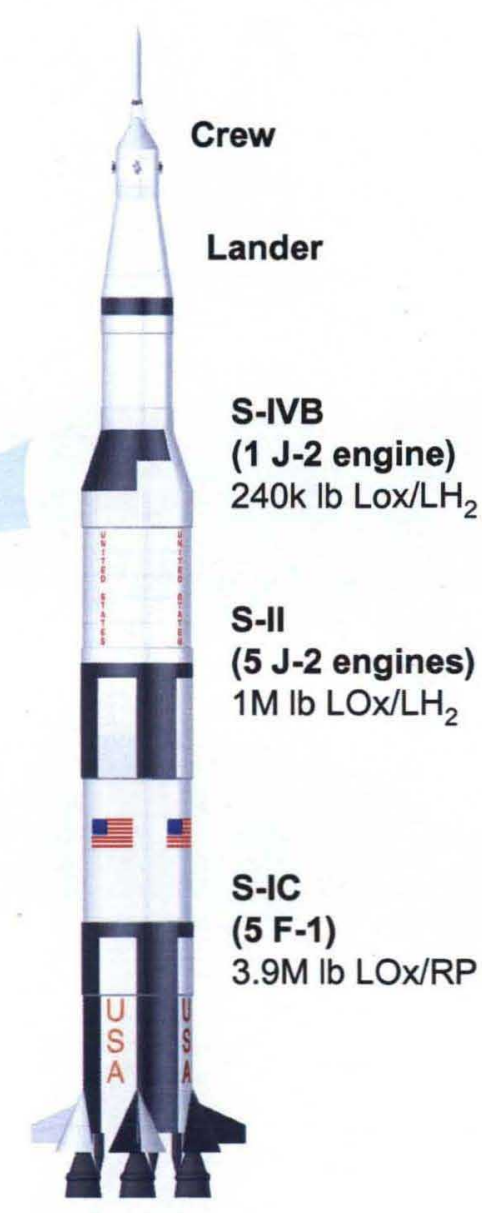

Saturn V

Height: $364 \mathrm{ft}$

Gross Liftoff Mass: $6.5 \mathrm{M} \mathrm{lb}$

$99 \mathrm{k} \mathrm{lbm}$ to TLI $262 \mathrm{k} \mathrm{lbm}$ to LEO 


\section{The Lunar Mission Scenario}

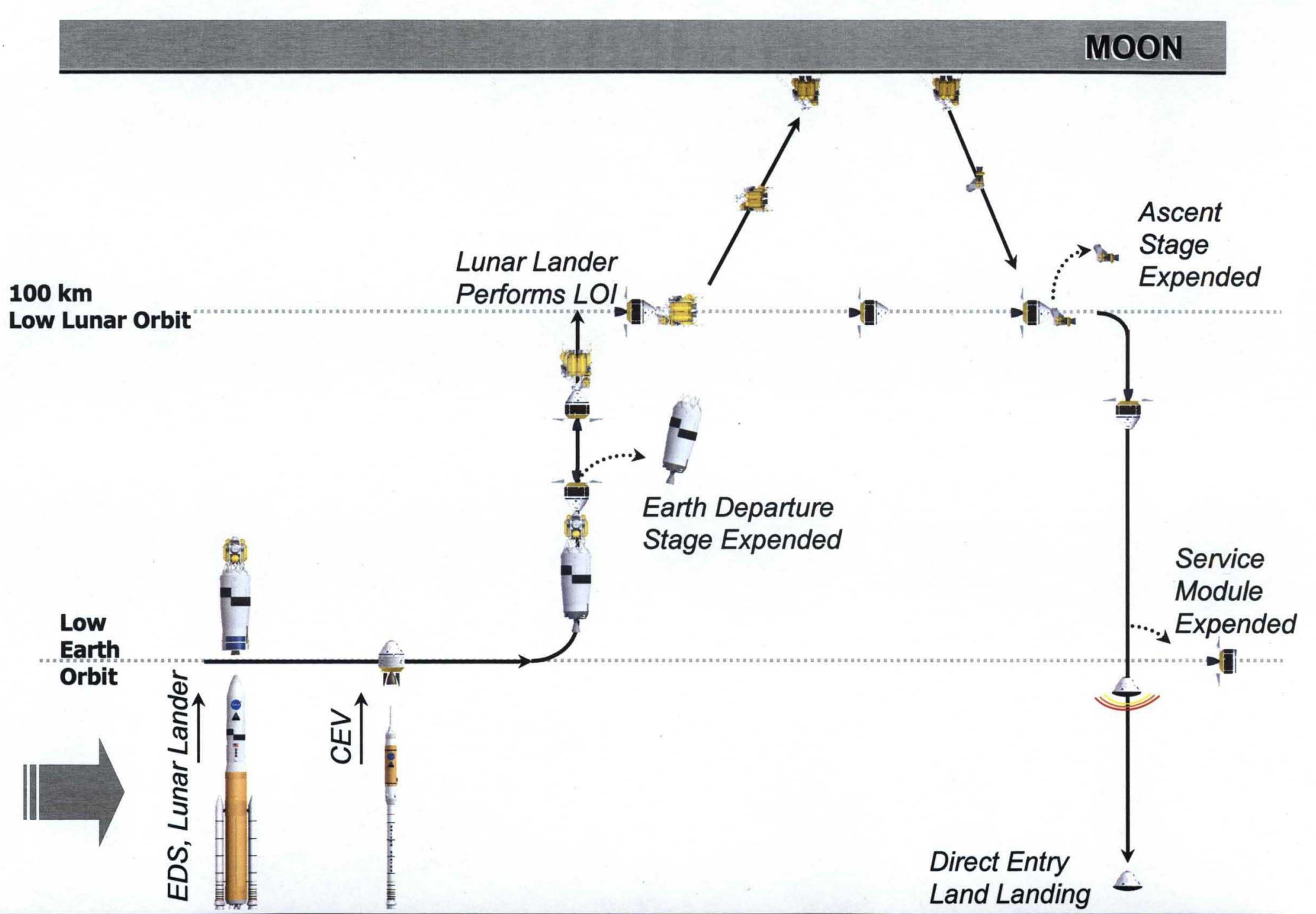

EARTH 


\section{Overview of the}

\section{Exploration Launch Projects Architecture}

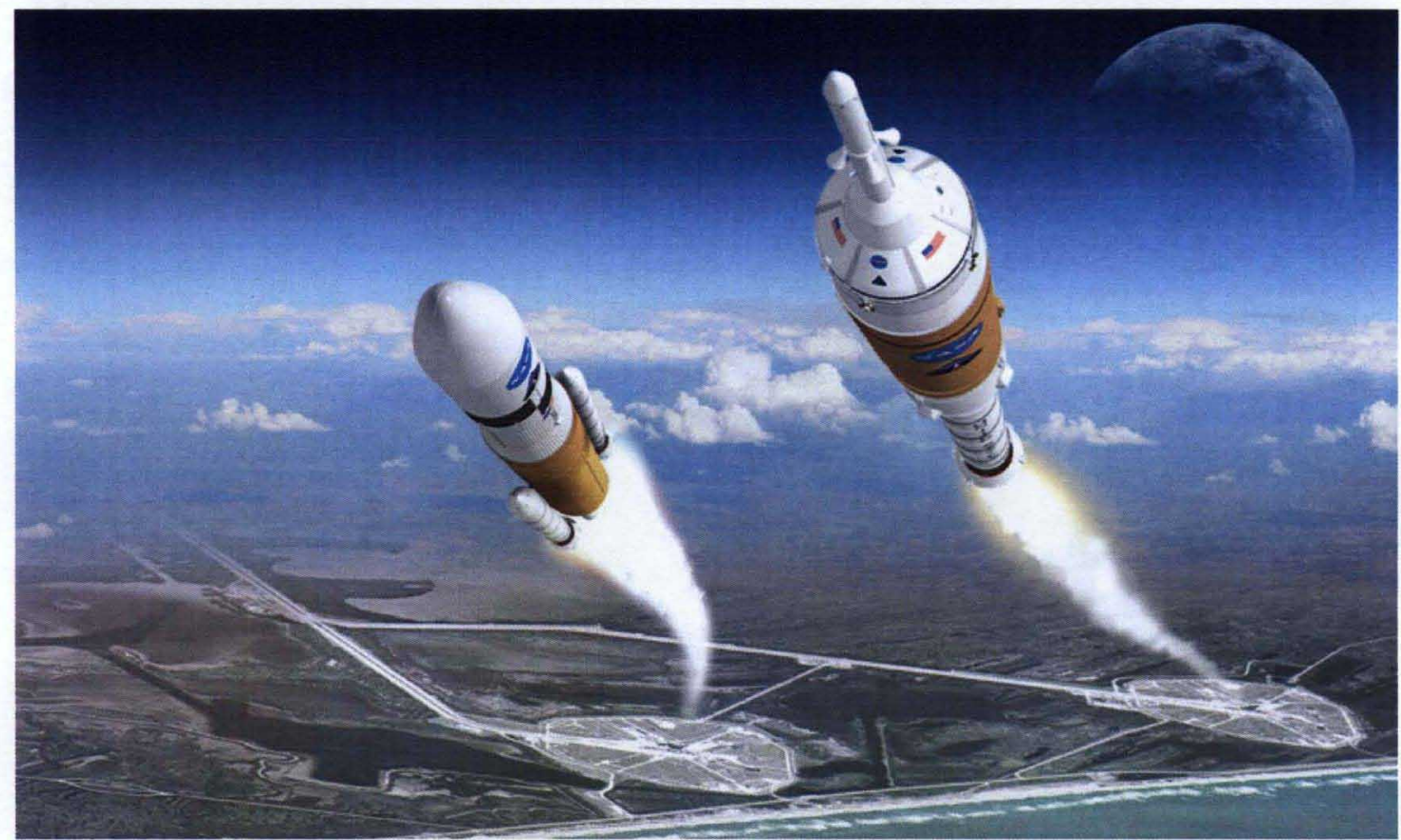

- Safe, reliable, affordable space transportation

- Based on heritage hardware and legacy knowledge

- Separates cargo from crew

- Ares V (left) delivers heavy exploration cargo to Low Earth Orbit (LEO)

- Ares I (right) delivers crew and cargo to LEO for International Space Station and lunar missions 


\section{Exploration Launch Projects Architecture (cont'd)}

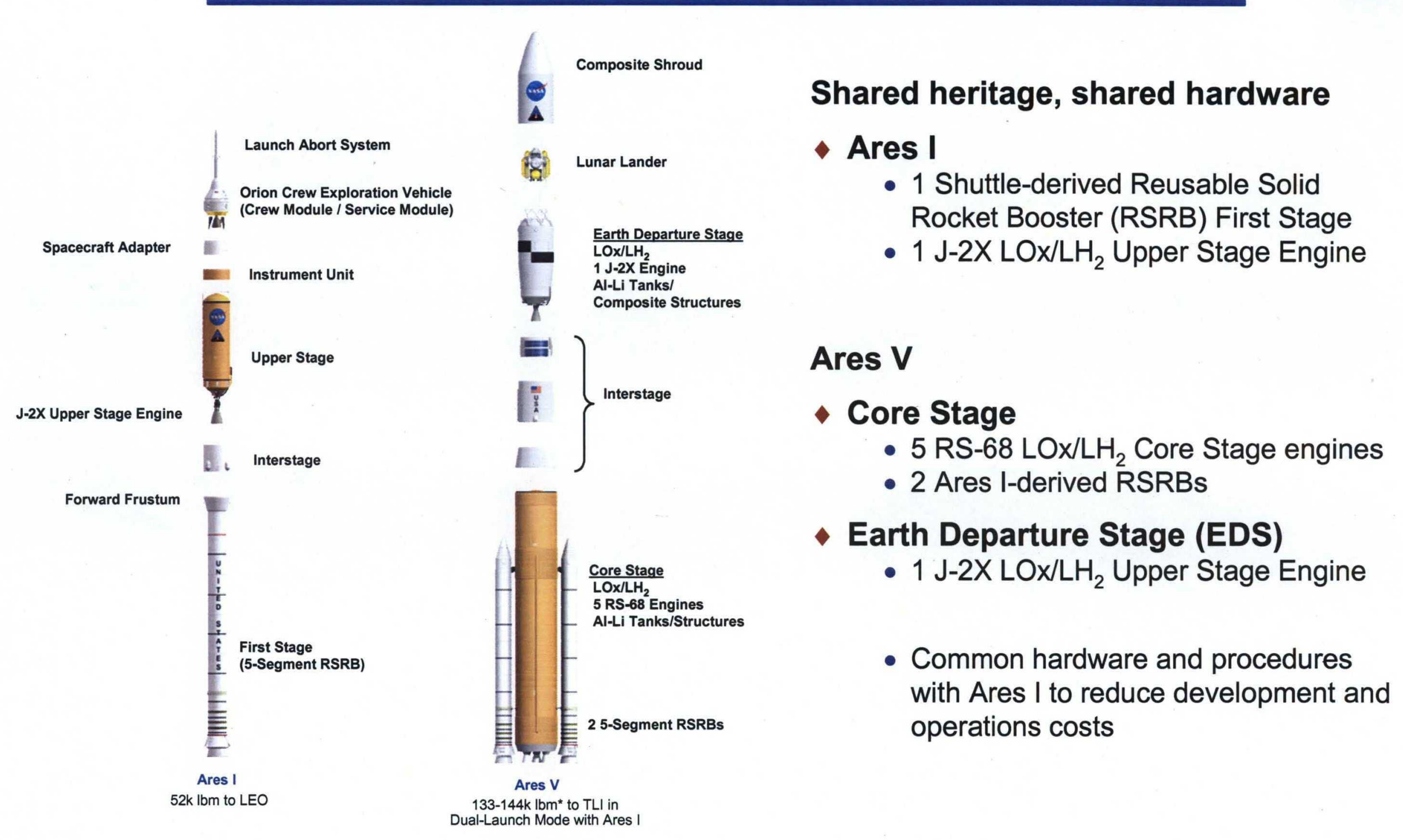

* Depending on length of on-orbit LEO loiter time 


\section{Ares $\mathbf{V}$ mission profile}
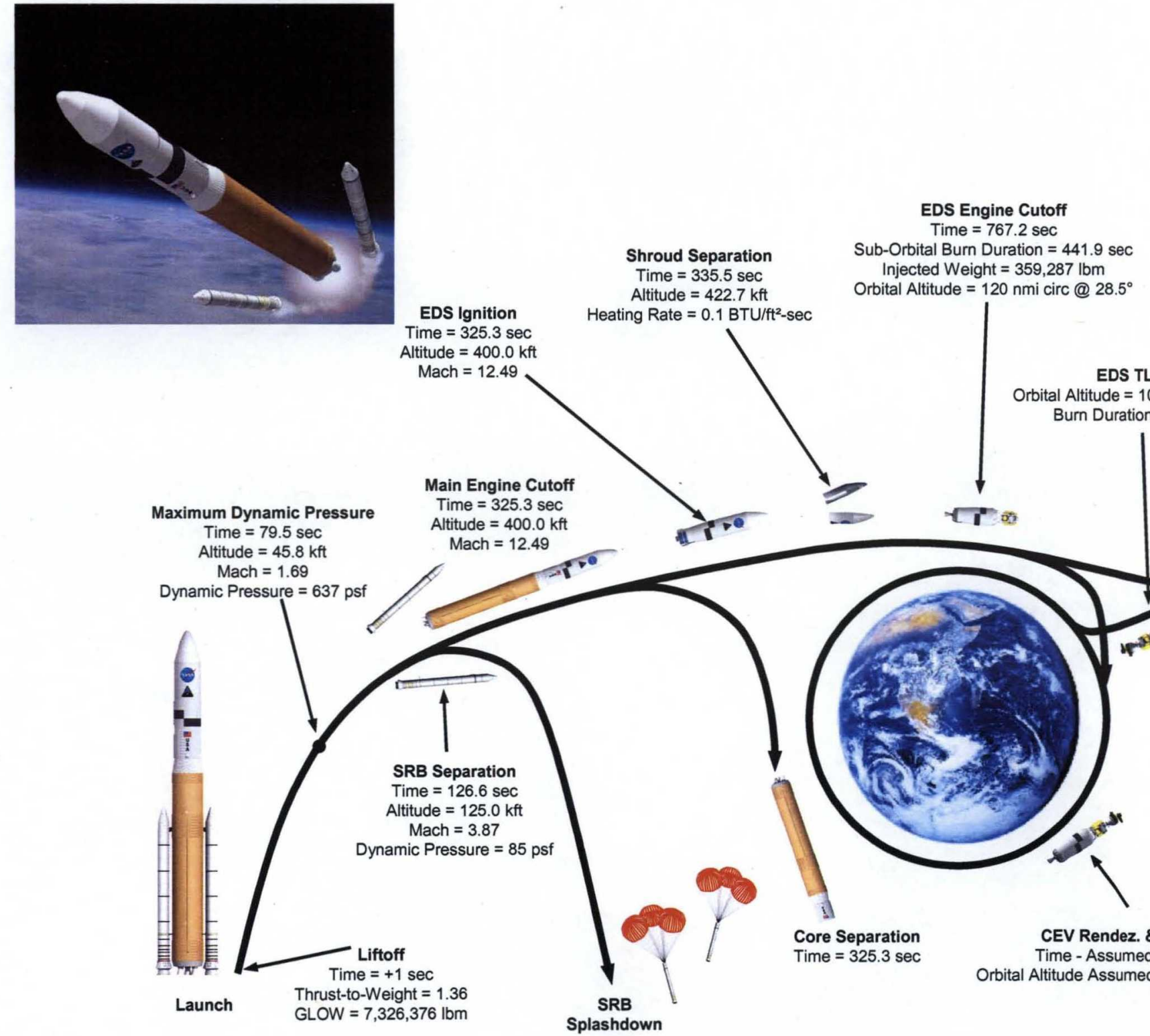

Altitude $=4227 \mathrm{kt}$

EDS Ignition
Time $=325.3 \mathrm{sec}$ Altitude $=400.0 \mathrm{kft}$ Mach $=12.49$

Heating Rate $=0.1 \mathrm{BTU} / \mathrm{ft}^{2}-\mathrm{sec}$

EDS TLI Burn

Orbital Altitude $=100 \mathrm{nmi}$ circ @ 28.5

Burn Duration $=309.0 \mathrm{sec}$
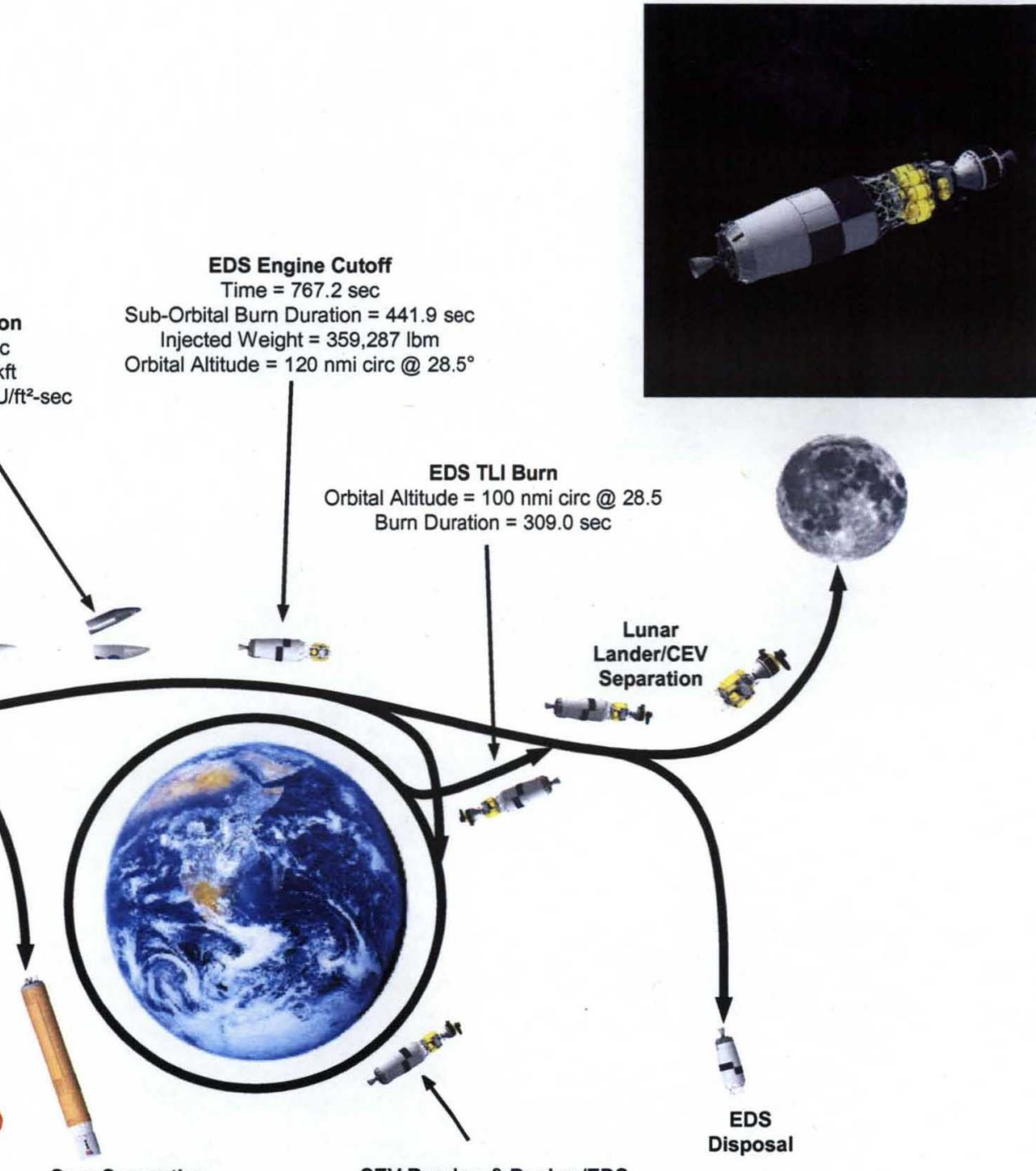

Core Separation

Time $=325.3 \mathrm{sec}$

CEV Rendez. \& Dock w/EDS

Time - Assumed Up to 14 Days

Orbital Altitude Assumed to Degrade to $100 \mathrm{nmi}$ 


\section{Refining the Concept}

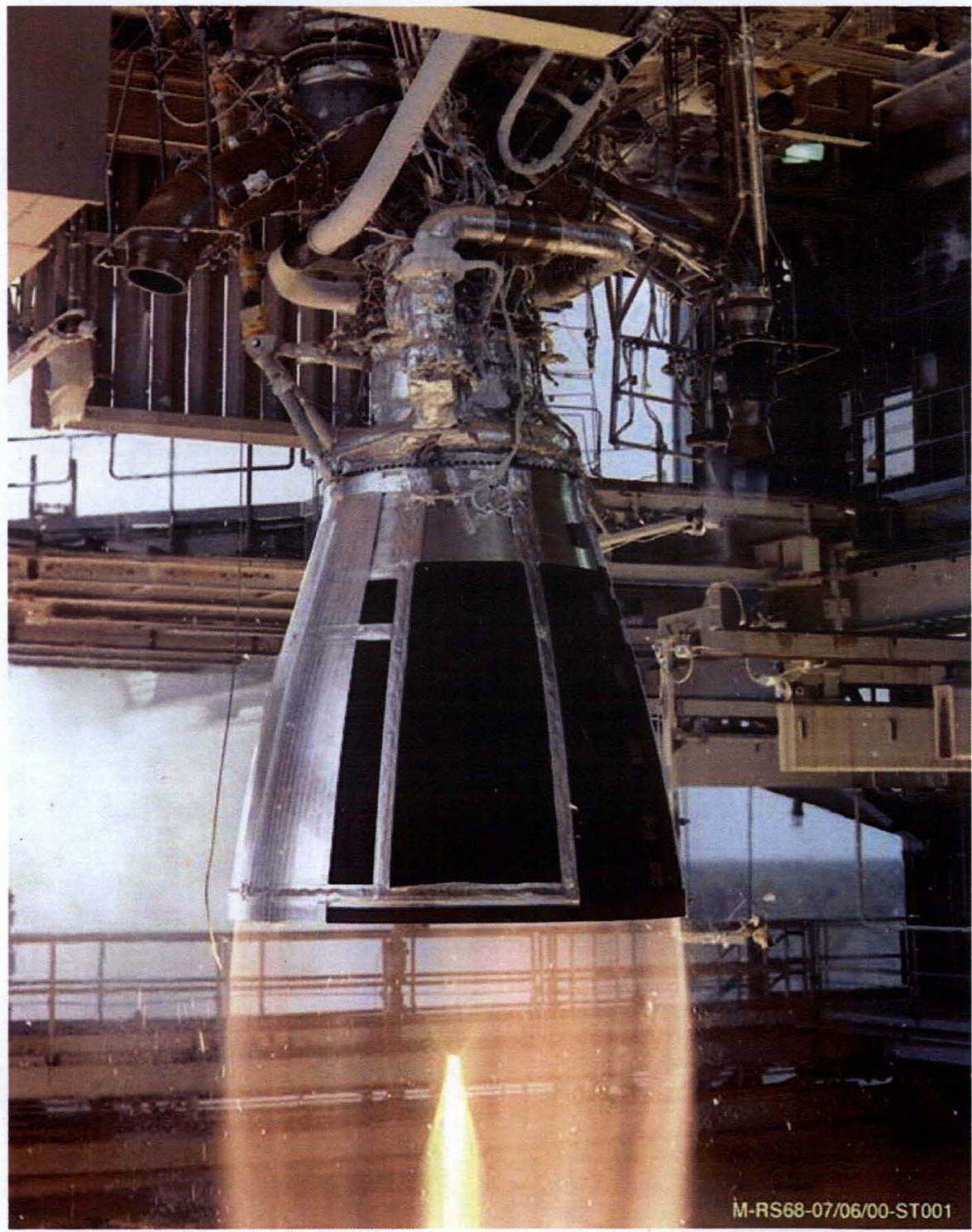

- Exploration System Architecture Study

- Ares V baseline: 2 RSRBs, 5 Space Shuttle Main Engines (SSMEs), 27.5 foot diameter Shuttle-derived Core Stage

- Bottom-Up Review

- RS-68 Expendable Exploration Launch Vehicle (EELV) engine replaces SSME

- Fewer parts

- Less labor

- Simpler to modify

- Synergy with USAF engine upgrades

- Delta IV flight experience reduces technical risk

- 33 foot diameter Saturn V-class Core Stage 


\section{Commonality: \\ Ares I First Stage to Ares V Booster}

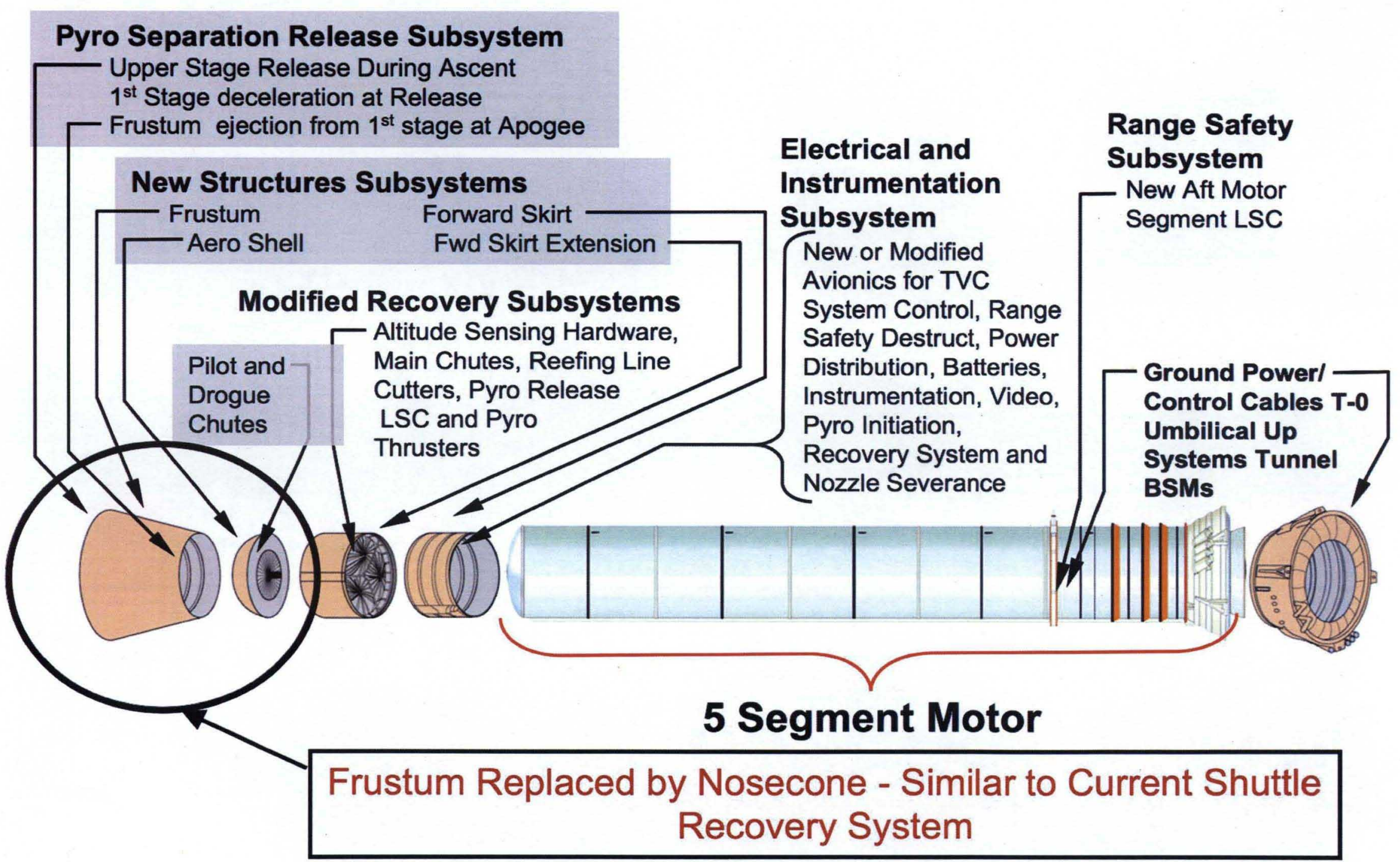




\section{Heritage Hardware: RS-68 Upgrades}

* Redesigned turbine nozzles to increase maximum power level by $\approx 4 \%$

Redesigned turbine seals to significantly reduce helium usage for pre-launch

Other RS-68A upgrades or changes that may be included:

- Bearing material change

- New Gas Generator igniter design

- Improved Oxidizer Turbo Pump temp sensor

- Improved hot gas sensor

- $2^{\text {nd }}$ stage Fuel Turbo Pump blisk crack mitigation

- Cavitation suppression

- ECU parts upgrade

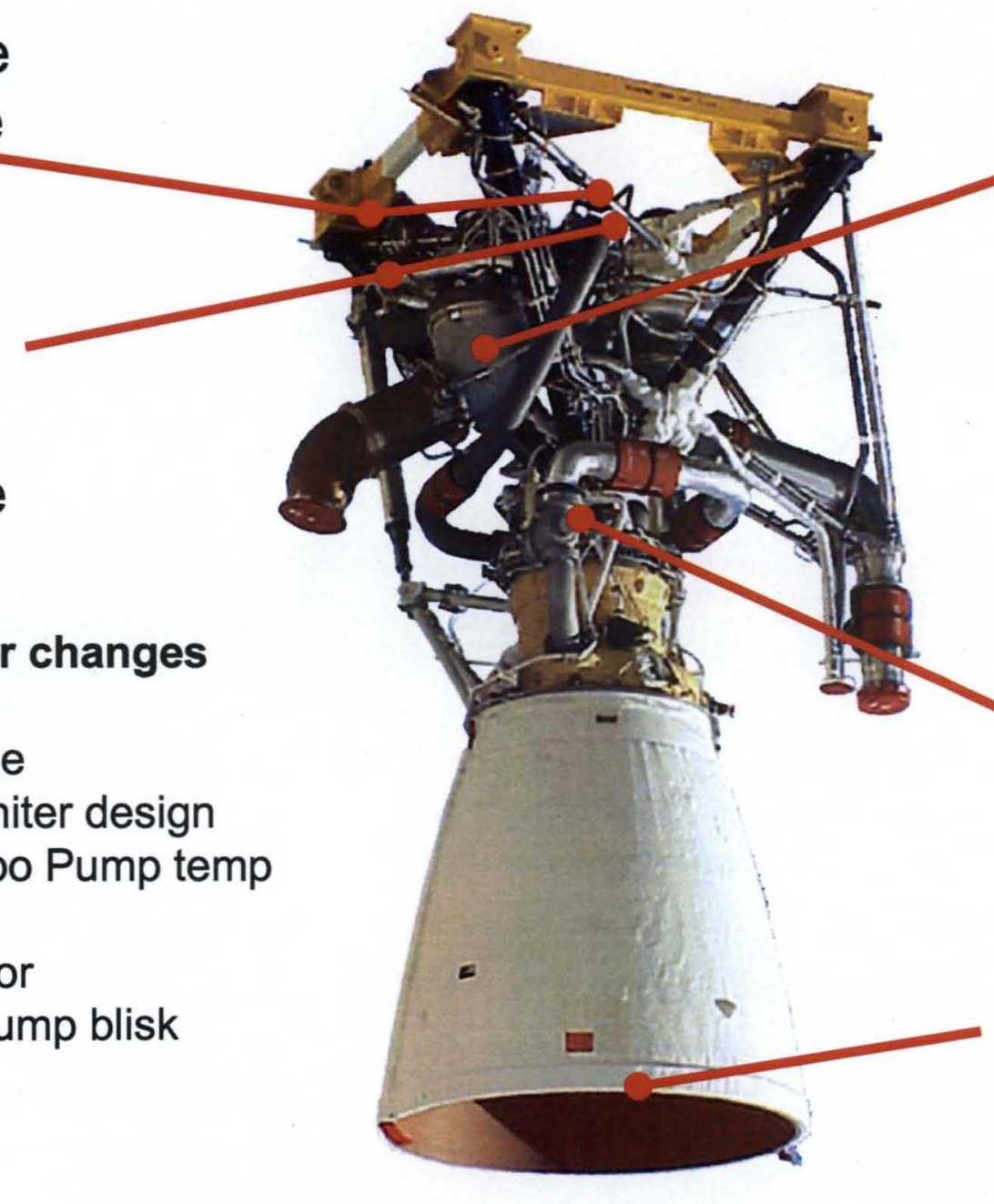

Helium spin-start duct redesign, along with start sequence modifications, to help minimize preignition free hydrogen

* Higher element density main injector improving specific impulse by $\approx 2 \%$ Increased duration capability ablative nozzle

${ }^{*}$ RS-68A Upgrades 


\section{Progress and Plans}

- Obtained "Seed money" for early development

- Developed integrated master schedule

- Prepared Concept of Operations document

- Performed Core Stage design studies
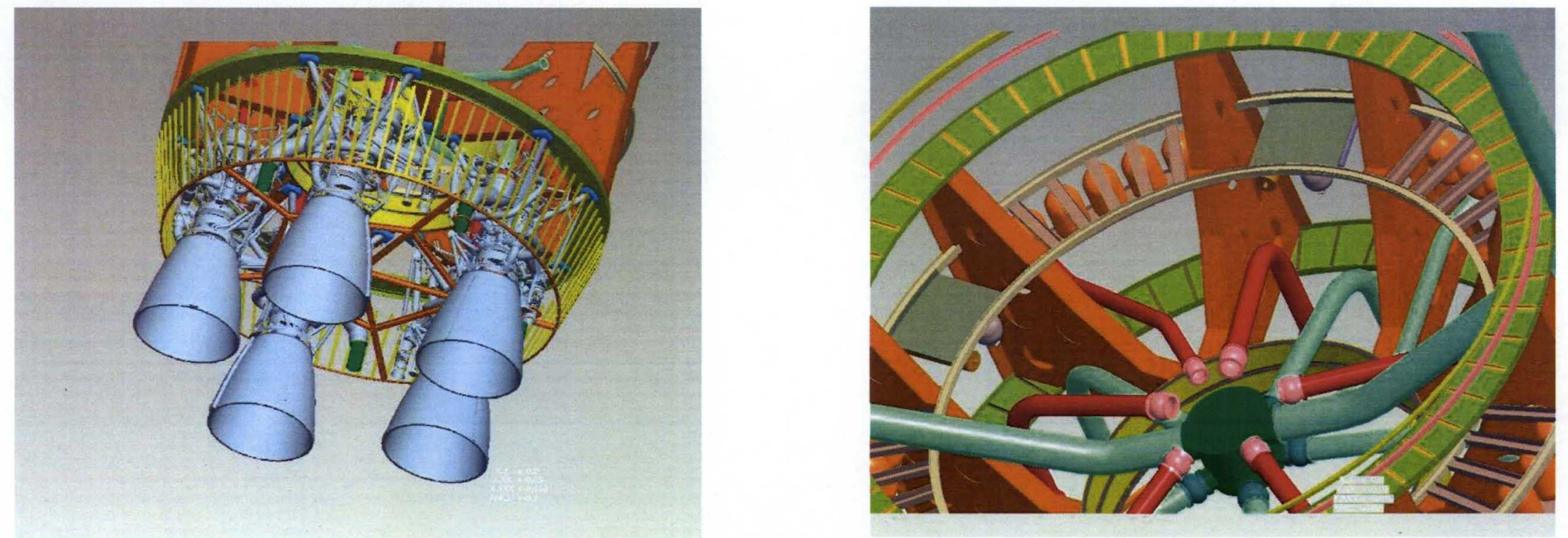


\section{Progress and Plans (cont'd)}

- Facilities studies - Michoud Assembly Facility (MAF), Stennis Space Center (SSC), Kennedy Space Center (KSC)

- Free hydrogen study
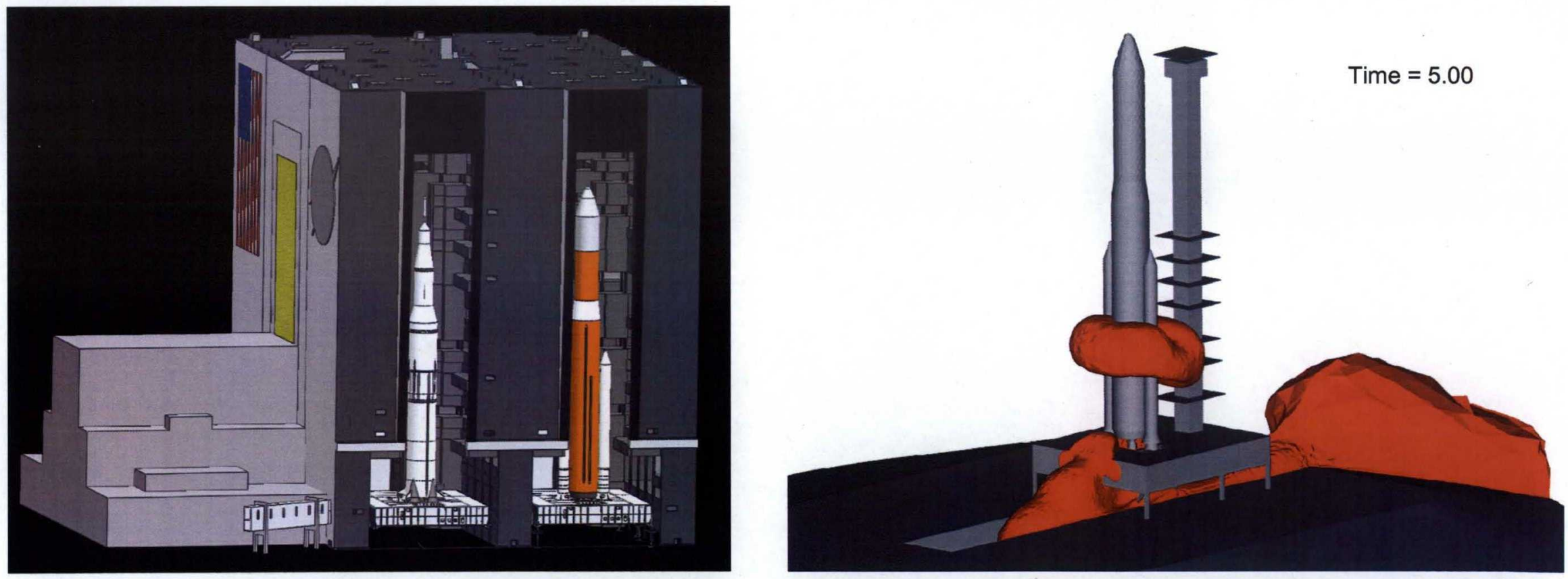


\section{Early Testing}
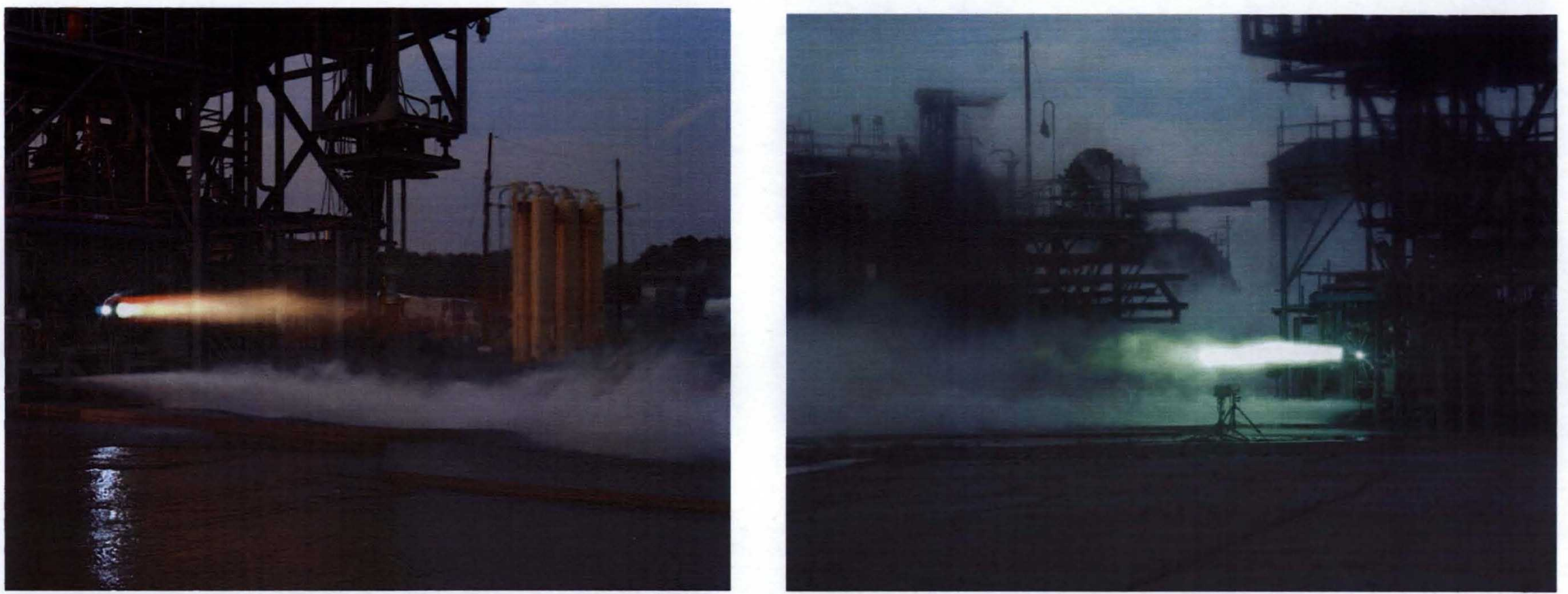

- RS-68 (left) and J-2X (right) subscale injector testing at MSFC, 2006-2007

- 29 RS-68-focused, 32 J-2X-focused

- 28-, 40-, \& 58-element injector inserts

- Thrust levels: less than 20,000 lbf

- Chamber pressures: $850-1,500$ psig

- Mixture Ratios: 4.8-6.9

- Fuel manifold temperatures: $100-300^{\circ}$.Rankin

- Commonality! 


\section{RSRB tests}

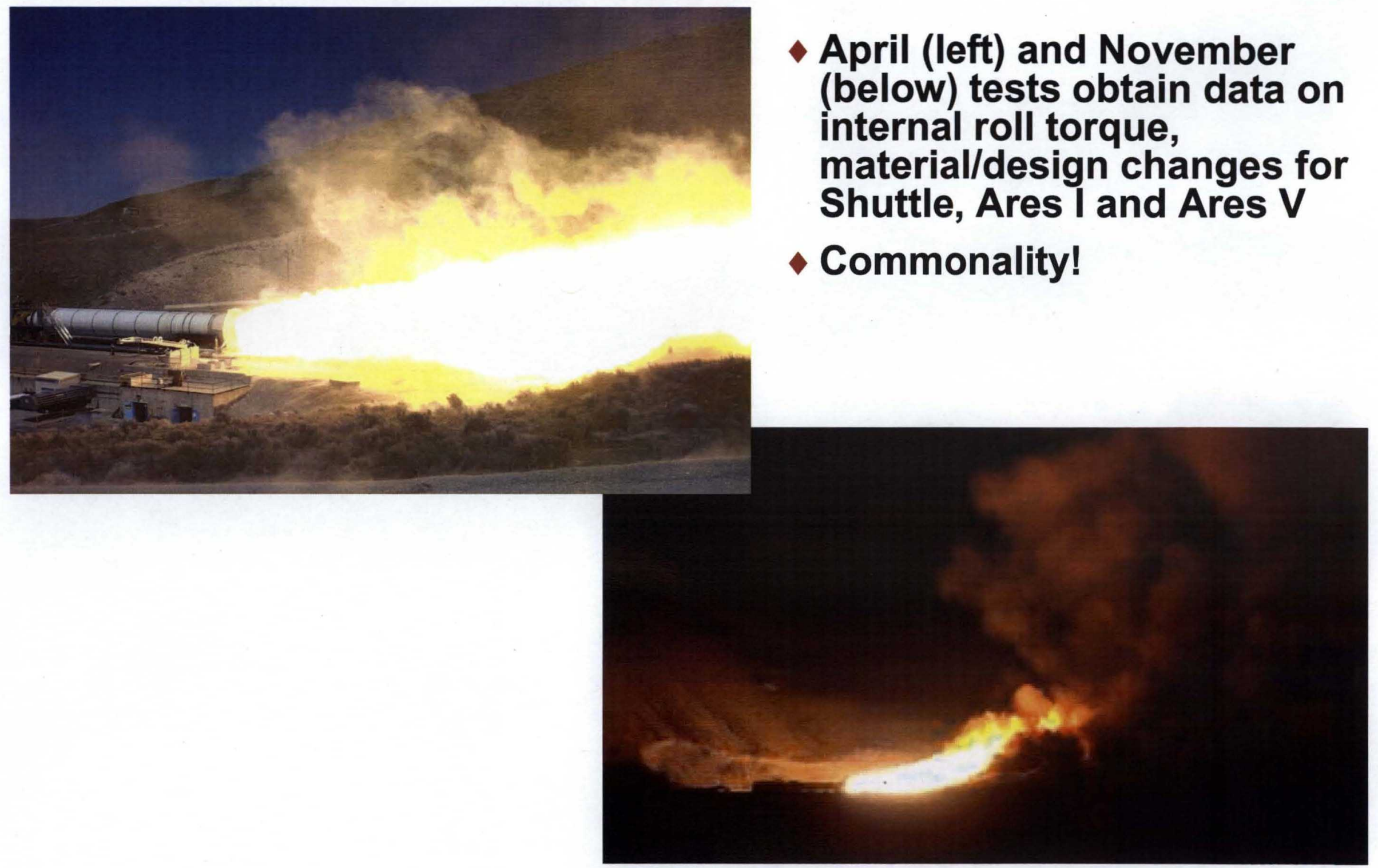




\section{Ares V Consolidated Schedule}

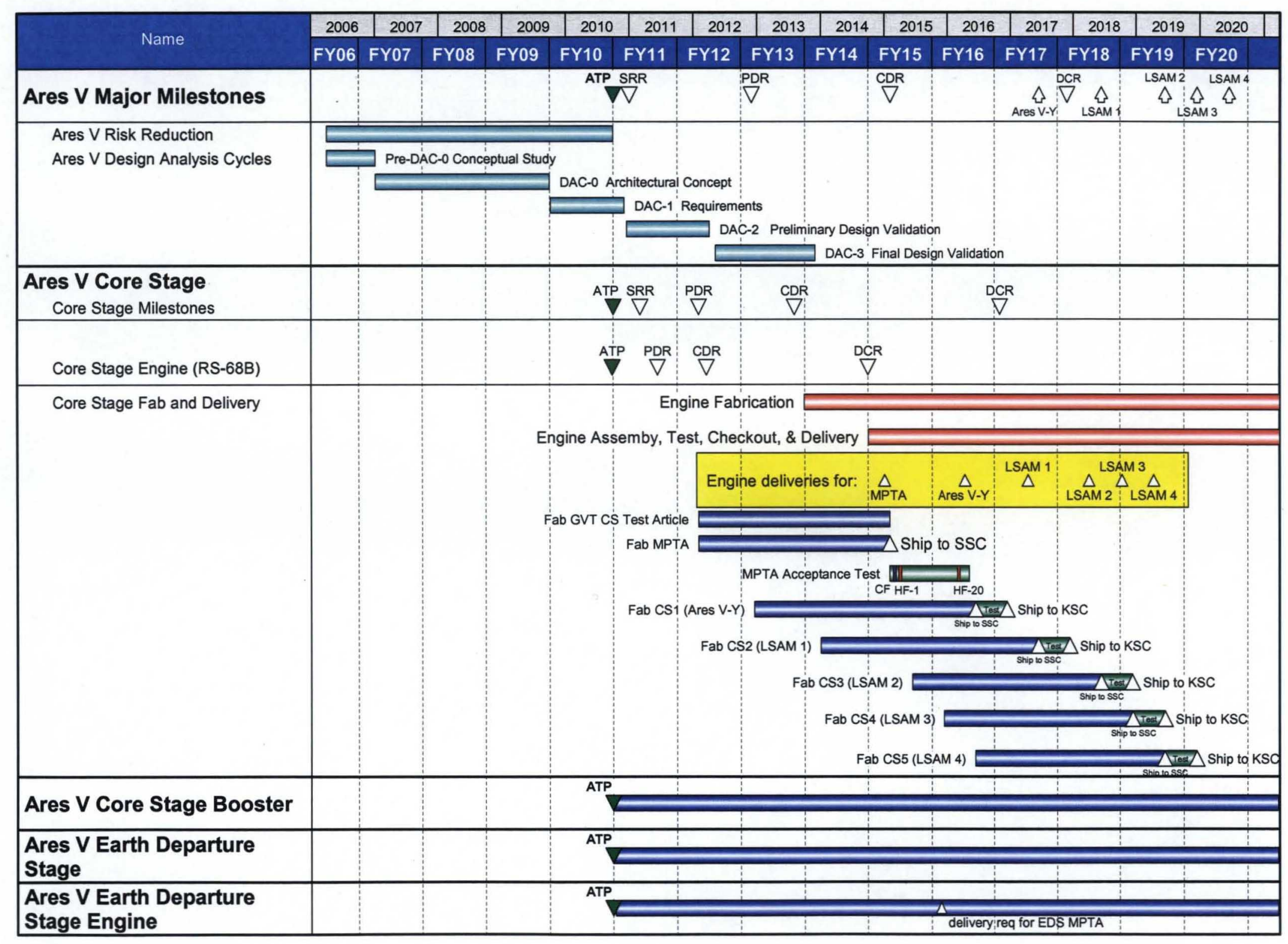




\section{Summary}

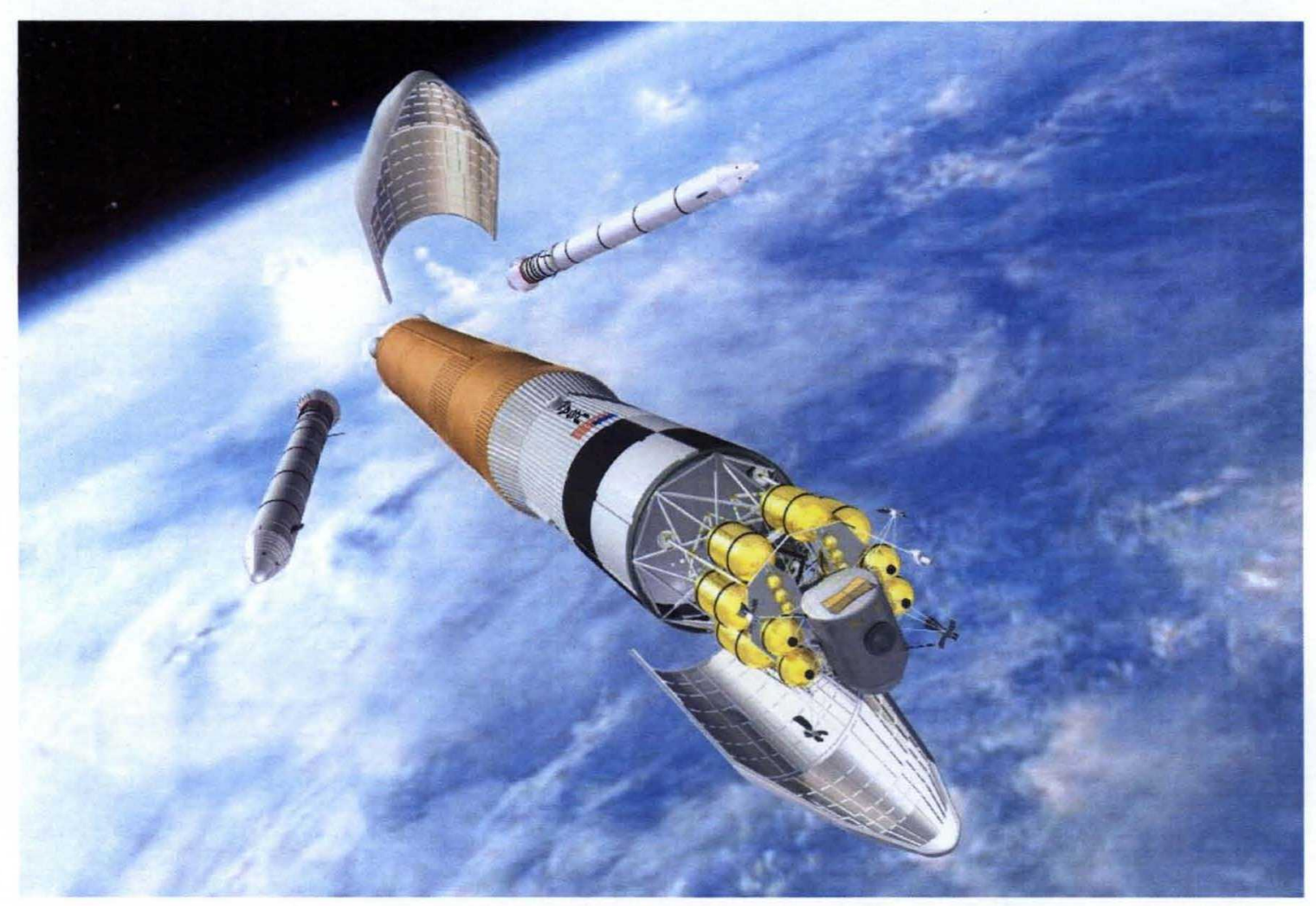

- Ares V remains the heavy-lift component of NASA's exploration architecture and a key component of "national strategy" 


\title{
For More Information
}

\author{
Phil Sumrall \\ John.P.Sumrall@NASA.Gov \\ (256) 544-3135
}

Ares public website

http://www.nasa.gov/ares

\section{Questions?}




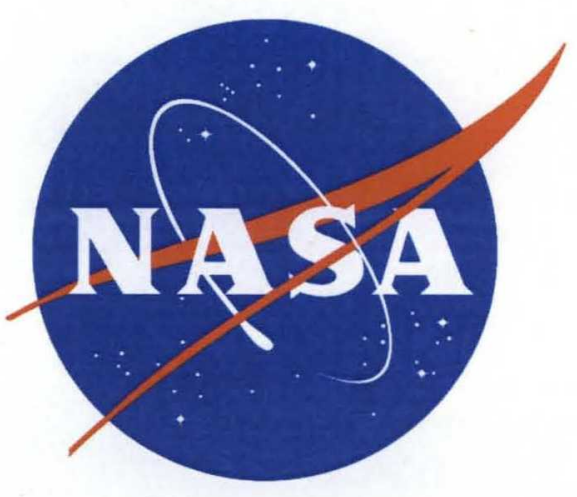

www.nasa.gov/ares 